\title{
Generation of Porous Alumina Layers in a Polydimethylsiloxane/Hydrogen Peroxide Medium on Aluminum Substrate in Corona Discharges
}

\author{
A. Groza, ${ }^{1}$ A. Surmeian, ${ }^{1}$ C. Diplasu, ${ }^{1}$ C. Luculescu, ${ }^{1}$ C. Negrila, ${ }^{2}$ and M. Ganciu ${ }^{1}$ \\ ${ }^{1}$ National Institute of Lasers, Plasma and Radiation Physics, Magurele, 077125 Bucharest, Romania \\ ${ }^{2}$ National Institute for Materials Physics, Magurele, 077125 Bucharest, Romania \\ Correspondence should be addressed to A. Groza; andreea@infim.ro
}

Received 2 July 2014; Accepted 1 August 2014; Published 3 September 2014

Academic Editor: Daniela Predoi

Copyright (C) 2014 A. Groza et al. This is an open access article distributed under the Creative Commons Attribution License, which permits unrestricted use, distribution, and reproduction in any medium, provided the original work is properly cited.

The porous alumina $\left(\mathrm{Al}_{2} \mathrm{O}_{3}\right)$ layer obtained at the interface between polydimethylsiloxane/hydrogen peroxide medium and aluminum substrate under charged and neutral species injection produced in negative corona discharges in air at atmospheric pressure is analyzed by different methods in this paper. The scanning electron microscopy investigations showed the uniform distribution of the pores formed in the alumina layer and their columnar structures. Both energy dispersive X-ray spectroscopy (EDS) and X-ray photoelectron spectroscopy (XPS) measurements indicate that during the anodization process of the aluminum in the polydimethylsiloxane/hydrogen peroxide medium in corona discharge the incorporation of silicon in the structure of the alumina layer is possible.

\section{Introduction}

The porous alumina $\left(\mathrm{Al}_{2} \mathrm{O}_{3}\right)$ layers are aluminum oxide films consisting of cylindrical pores arranged parallel to each other.

By conventional methods, these layers are prepared by an anodization process, namely, the electrochemical oxidation of aluminum films in acid reactive medium under direct current conditions. Although the chemical and physical aspects of this process are not completely understood, it is generally accepted that the porous form of the alumina layer is produced in two steps: (a) growth of an aluminum oxide at the alumina/ $\mathrm{Al}$ interface due to the counter migration of $\mathrm{Al}^{3+}$, $\mathrm{OH}^{-}$, and $\mathrm{O}^{2-}$ ions and (b) dissolution of aluminum oxide at alumina film/solution interface [1].

Recent research studies in the field of anodization methods of aluminum were directed toward alternative methods for the generation of alumina layers, namely, corona discharge treatments [2]. Running of these kinds of discharges in air at atmospheric pressure has the unique advantage of simultaneous production of charged (negative or positive ions) and neutral (e.g., $\mathrm{O}_{3}$ ) species of oxygen known for their reactive character in the interaction with materials.

Over the time, alumina layers have been intensely studied due to their widespread application in corrosion protection for aerospace, automotive, architectural, or packaging [2]. Their nontoxic and biocompatible properties make them also attractive for biotechnological applications [3]. Alumina nanoparticles can be trapped and studied in electromagnetic fields $[4,5]$ and are of great interest for their antimicrobial activity and their possible clinical applications [6].

As substrates, porous anodic $\mathrm{Al}$ oxide layers can improve the adherence of different types of thin layers [7-9]. On the other hand, a PDMS layer deposited on an anodized porous $\mathrm{Al}$ oxide layer [10] could act as an effective barrier preventing the contact of water based corrosive media with the underlying metallic surfaces $[11,12]$.

In our previous papers, we showed that, during the polymerization of a polydimethylsiloxane (PDMS) liquid film lying on the surface of an aluminum substrate in corona discharge, an $\mathrm{Al}$ oxide layer is generated at polymer/substrate 


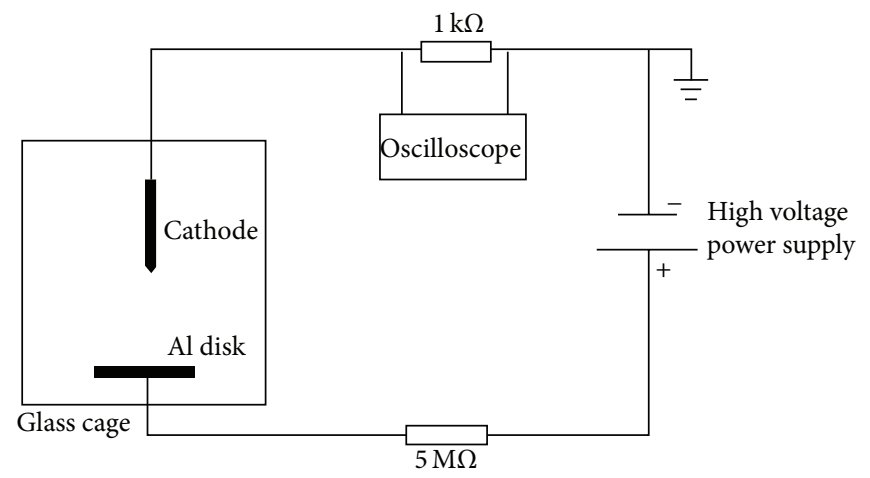

FIgURE 1: Experimental setup.

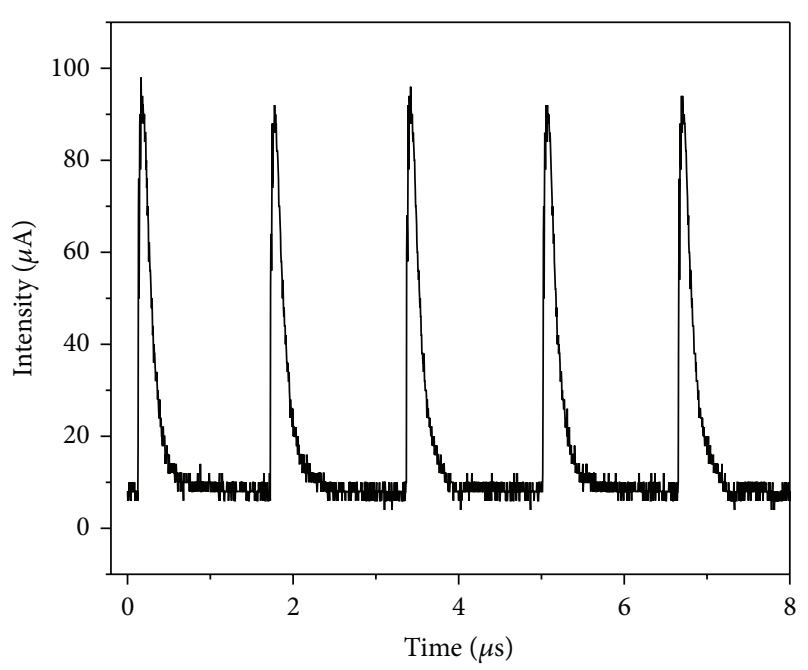

FIGURE 2: Waveform of the discharge current in the Trichel pulse regime.

interface [10]. The $\mathrm{OH}$ and $\mathrm{Si}-\mathrm{OH}$ groups present at polymer/substrate interface determine the formation of Si-O$\mathrm{Al}$ bonds announcing the possibility of counter migration of $\mathrm{Si}$ and $\mathrm{Al}$ atoms. The aluminum oxide layer has porous structure, the pores having a nonuniform distribution on the alumina layer [13]. The dependence of the pores structure on the corona discharge current values $[14,15]$ and the formation of the Si-O-Al bonds evidenced the existence of an anodization process at polymer/ $\mathrm{Al}$ substrate interface.

Responsible for oxidation of the $\mathrm{Al}$ surface in negative corona discharge are the negative ions of oxygen $\mathrm{O}_{2}{ }^{-}, \mathrm{O}_{3}{ }^{-}$, $\mathrm{O}_{4}{ }^{-}, \mathrm{CO}_{2}{ }^{-}$, and $\mathrm{CO}_{3}{ }^{-}$), the water, and consequently the $\mathrm{OH}$ radicals present either in liquid or in solid film further formed on the substrate due to the PDMS polymerization process [10]. Even these species are able to generate an anodization process of the $\mathrm{Al}$ in a similar way with the classical one; the nonuniform distribution of the pores structure in the alumina layer suggests that the experimental conditions need further improvements.

In this paper, we report for the first time a uniform distribution of the pores in the alumina layer generated in corona discharge operating conditions by mixing the hydroxyl terminated PDMS liquid precursor with hydrogen peroxide $\left(\mathrm{H}_{2} \mathrm{O}_{2}\right)$. In this way, the water molecules and the density of $\mathrm{OH}$ radicals at $\mathrm{Al}$ substrate interface are enhanced, knowing that hydrogen peroxide can be involved in the following reactions:

$$
\begin{aligned}
& \mathrm{H}_{2} \mathrm{O}_{2} \rightarrow \mathrm{H}_{2} \mathrm{O}+1 / 2 \mathrm{O}_{2}[16], \\
& \mathrm{OH}+\mathrm{H}_{2} \mathrm{O}_{2} \rightarrow \mathrm{H}_{2} \mathrm{O}+\mathrm{HO}_{2} \text { [17], } \\
& \mathrm{HO}_{2}+\mathrm{H}_{2} \mathrm{O}_{2} \rightarrow \mathrm{O}_{2}+\mathrm{H}_{2} \mathrm{O}+\mathrm{OH}[17], \\
& 2 \mathrm{O}_{3}+\mathrm{H}_{2} \mathrm{O} \rightarrow \mathrm{OH}+\mathrm{O}_{2}+\mathrm{HO}_{2} \text { [17] }
\end{aligned}
$$

The morphology, the elemental composition, and the processes which determine the porous alumina layer formation in negative corona discharge in the presence of a $\mathrm{PDMS} / \mathrm{H}_{2} \mathrm{O}_{2}$ chemical medium are investigated by scanning electron microscopy (SEM), electron dispersion spectroscopy (EDS), and X-ray photoelectron spectroscopy (XPS).

\section{Materials and Methods}

2.1. Description of the Experimental Conditions Used for the Generation of the Porous Alumina Layers. The experimental setup used for the operating of the negative corona discharge in a Trichel pulse regime is presented in Figure 1. It consists in a point to plane corona discharge electrode configuration, the distance between electrodes being $10 \mathrm{~mm}$. The cathode is a $20 \mathrm{~mm}$ tungsten wire placed perpendicular to the centre of the anode (plane electrode) in a glass cage in air at atmospheric pressure. As anode, we used an $\mathrm{Al}$ disk electrode with a diameter of $10 \mathrm{~mm}$. A high voltage of $11 \mathrm{kV}$ was applied between electrodes, through a resistor of $5 \mathrm{M} \Omega$, the mean value of the discharge current being $40 \mu \mathrm{A}$.

The negative ions of oxygen $\mathrm{O}_{2}^{-}, \mathrm{O}_{3}^{-}, \mathrm{O}_{4}^{-}, \mathrm{CO}_{2}^{-}$, and $\mathrm{CO}_{3}{ }^{-}$produced in the Trichel regime of the negative corona discharge in the vicinity of the cathode [18] travel to the anode in regular packages. The transport of these particles through the interelectrodic gap have a pulsating nature due to the periodical character of positive/negative ions production respectively destruction processes occurring at the cathode. Thus, the corona discharge current, Figure 2, is formed by regular pulses with a period of about $1.5 \mu$ s. 


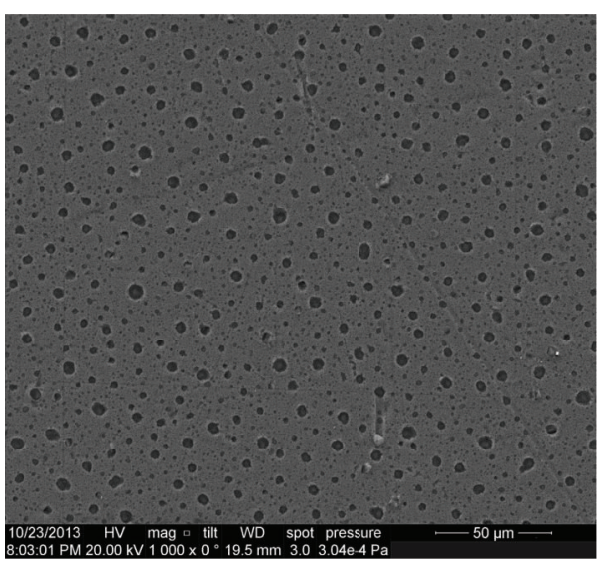

(a)

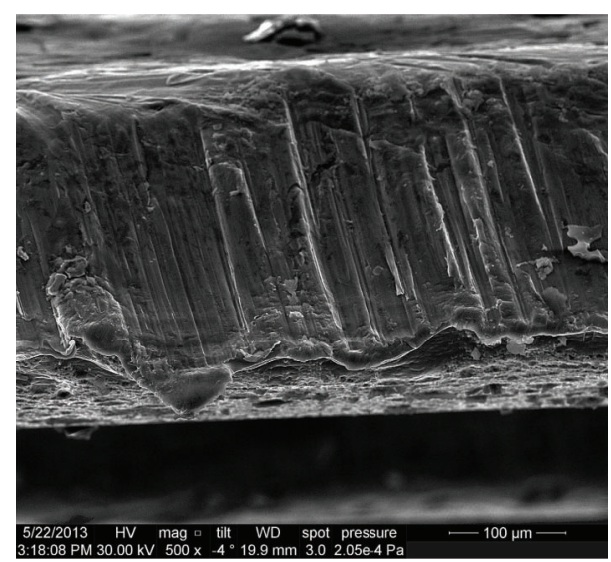

(b)

FIGURE 3: SEM images of (a) porous anodic Al oxide layer and (b) transversal section of the alumina layer.

Due to the uniformity of the current density distribution on the anode surface and to the $\mathrm{O}_{2}{ }^{-}, \mathrm{O}_{3}{ }^{-}, \mathrm{O}_{4}{ }^{-}, \mathrm{CO}_{2}{ }^{-}$, and $\mathrm{CO}_{3}{ }^{-}$negative ions production, the Trichel pulse regime of the corona discharge is proper to be used for thin film generation [10]. It was shown [19] that, in a Trichel pulse regime, the distribution of the current density on the plane electrode is uniform on a circular surface with a radius given by the relation $r=\sqrt{3} d$, where $d$ is the interelectrode gap. In our experimental conditions $r=17.2 \mathrm{~mm}$.

Previously [10], we showed that a drop of $0.1 \mu \mathrm{L}$ hydroxyl terminated polydimethylsiloxane (PDMS) liquid precursor stretched on an $\mathrm{Al}$ substrate in negative corona discharge is transformed into a solid polymer layer after 2 hours. As a result of the polymerization process, water molecules are generated in the PDMS layer. They can be decomposed under the influence of corona electric fields and associated charges injection generating $\mathrm{OH}$ radicals in the polymer. The $\mathrm{Si}-\mathrm{OH}$ groups present also in the PDMS layer have proved their utility in the generation of Si-O-Al bonds at polymer/Al substrate interface. In the same time, at polymer/Al substrate interface an anodization process occurs. The negative ions of oxygen produced in corona discharge, the water molecules and the $\mathrm{OH}$ groups resulting as byproducts of the polymerization process [10] are mainly responsible for the alumina layer formation.

In experimental conditions described above, we placed a $10 \mu \mathrm{L}$ of liquid precursor on an optical polished $\mathrm{Al}$ substrate (anode). This liquid precursor contains a proportion of 33\% PDMS with hydroxyl end groups and 67\% hydrogen peroxide $\left(\mathrm{H}_{2} \mathrm{O}_{2}\right)$. The addition of $\mathrm{H}_{2} \mathrm{O}_{2}$ to the PDMS liquid precursor does not change the electrical regime of the corona discharge and its optical characteristics. Under negative corona charge injection, the stretch of the PDMS liquid assures the uniform covering of the substrate with the $\mathrm{H}_{2} \mathrm{O}_{2}$. The further decomposition of $\mathrm{H}_{2} \mathrm{O}_{2}$ in negative corona discharge produced in air gives an enhanced infusion of water molecules and $\mathrm{OH}$ radicals at the surface of the $\mathrm{Al}$ substrate.

The solid layer formed after 5 hours of irradiation in negative corona discharge of the $\mathrm{PDMS} / \mathrm{H}_{2} \mathrm{O}_{2}$ has been chemically removed. Thus, the anodization processes of the Al substrate were revealed through the morphology and elemental composition analysis of porous anodic $\mathrm{Al}$ oxide layer.

2.2. SEM Measurements. The morphology of the alumina layers has been investigated using a FEI Inspect $S$ scanning electron microscope in both high- and low-vacuum modes.

2.3. EDS Measurements. Elemental composition analysis was performed by energy dispersive $\mathrm{X}$-ray spectroscopy using an EDAX Inc. SiLi detector attached inside the scanning electron microscope. The measurements were performed at a voltage of $10 \mathrm{kV}$.

2.4. XPS Measurements. The X-ray photoelectron spectroscopy (XPS) measurements were performed using a VG ESCA 3 MK II XPS installation $(E k \alpha=1486.7 \mathrm{eV})$. The vacuum analysis chamber pressure was $p=3 \times 10^{8}$ torr. The XPS recorded spectrum involved an energy window $w=$ $20 \mathrm{eV}$ with the resolution $R=50 \mathrm{eV}$ with 256 recording channels. The XPS spectra were processed using Spectral Data Processor v 2.3 (SDP) software. The measured binding energy (BE) scale was referenced to a $C 1$ s peak at the $B E$ value of $284.8 \mathrm{eV}$ [20]. The accuracy for BE assignments is $\pm 0.2 \mathrm{eV}$.

\section{Results and Discussions}

3.1. SEM Investigations. In our previous papers $[10,14,15]$ we showed that the pores formed into the alumina layer during the polymerization process of the PDMS liquid precursor on $\mathrm{Al}$ substrate in negative corona discharge do not present uniform and regular structures.

In the present paper, by matching the current intensity $(40 \mu \mathrm{A})$ with the liquid precursor's composition (33\% PDMS with hydroxyl end groups and $67 \% \mathrm{H}_{2} \mathrm{O}_{2}$ ) and with the operating time of the negative corona discharge (5 hours), we succeed to generate a uniform distribution of the pores 


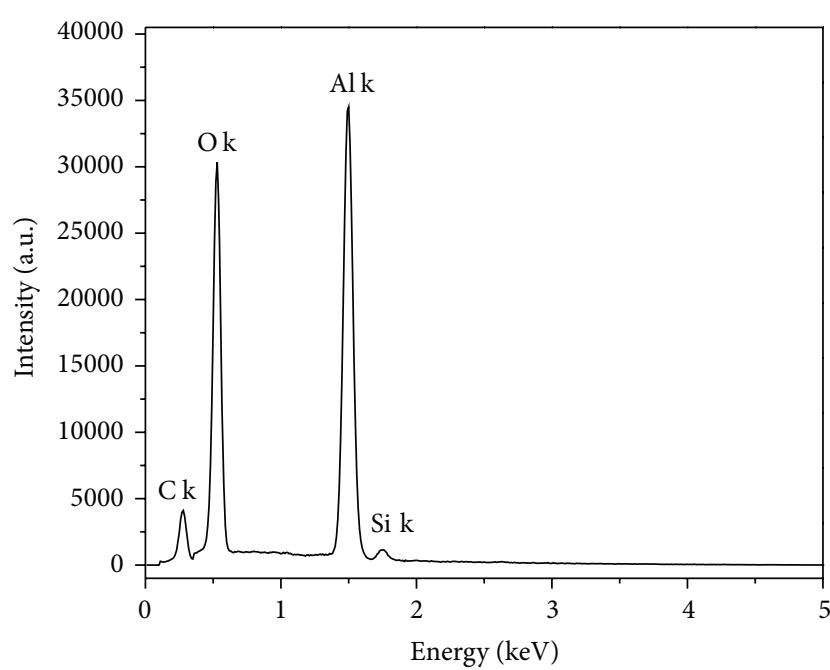

FIGURE 4: EDS spectrum of porous anodic $\mathrm{Al}$ oxide layer.

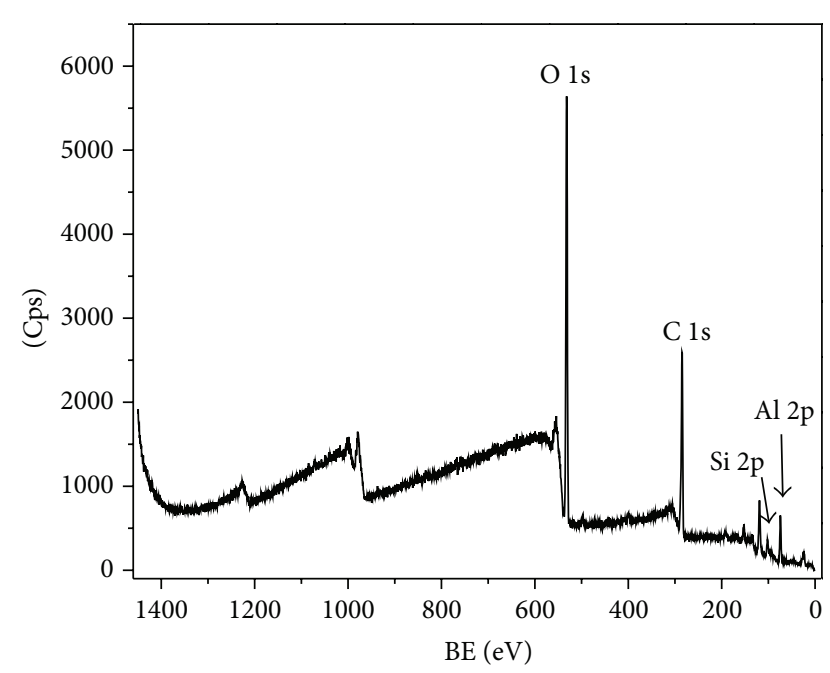

FIGURE 5: XPS wide scan energy spectrum of the alumina layer.

in the anodic $\mathrm{Al}$ oxide layer, Figure 3(a). The columnar structure of these pores is revealed in Figure 3(b). Thus, under the experimental conditions presented above, the uniform injection of the negative oxygen ions into a liquid/layer rich in water molecules and $\mathrm{OH}$ groups is proper for the generation in a controllable manner of an advanced anodization process (columnar structure formation [20]) of the $\mathrm{Al}$ substrate.

3.2. EDS Investigations. The establishment of the elements contained in the porous alumina layer is important in order to determine the mechanisms responsible for the anodization of the $\mathrm{Al}$ substrate.

In Figure 4, the EDS spectrum of the porous anodic $\mathrm{Al}$ oxide layer displayed in Figure 3 is presented. It can be observed that, besides the peaks of $\mathrm{Al}$ and $\mathrm{O}$, a peak char- acteristic to Si atoms appears in this spectrum. As in the SEM image from Figure 3(a), there are no residual pieces of polymer on the surface of porous $\mathrm{Al}$ oxide layer; it means that during the anodization process of the substrate the $\mathrm{Si}$ atoms are incorporated into the anodic $\mathrm{Al}$ oxide layer

3.3. XPS Investigations. The chemical processes induced by the PDMS $/ \mathrm{H}_{2} \mathrm{O}_{2}$ into the $\mathrm{Al}$ substrate were investigated by $\mathrm{X}$-ray photoelectron spectroscopy (XPS) measurements.

The XPS spectrum of the porous anodic Al oxide layer is displayed in Figure 5.

In order to better reveal the processes that take place during the anodization of $\mathrm{Al}$ substrate in corona discharge in the presence of $P D M S / \mathrm{H}_{2} \mathrm{O}_{2}$, we applied a peak fitting analysis for the experimental bands specific to the $\mathrm{Al} 2 \mathrm{p}, \mathrm{Si}$ $2 p$, and O 1s XPS peaks. For each peak, we used as fitted curve a Gaussian type profile curve.

The experimental XPS bands characteristic to $\mathrm{Al} 2 \mathrm{p}, \mathrm{Si}$ $2 \mathrm{p}$, and $\mathrm{O} 1 \mathrm{~s}$ together with the fitted curves are presented in Figure 6. The intensity of the deconvoluted XPS band from $73.6 \mathrm{eV}$ belonging to $\mathrm{Al}_{2} \mathrm{O}_{3}$ [21] is almost the same with that one located at $74.9 \mathrm{eV}$ and assigned to aluminosilicates $\left(\mathrm{Al}_{2} \mathrm{SiO}_{5}\right)$, Figure 6(a) [22].

The deconvolution of the Si $2 p$ XPS peak reveals the nature of the $\mathrm{Si}$ incorporated into the anodic $\mathrm{Al}$ oxide porous layer. The presence of the $99.8 \mathrm{eV}(\mathrm{Si}), 101.3 \mathrm{eV}(\mathrm{SiO})$ [23], $102.8 \mathrm{eV}\left(\mathrm{Al}_{2} \mathrm{SiO}_{5}\right)$ [24], and $104.2 \mathrm{eV}\left(\mathrm{SiO}_{2}\right)$ [25] XPS bands in the $\mathrm{Si} 2 \mathrm{p}$ spectrum from Figure 6(b) indicates how $\mathrm{Si}$ atoms are linked in the porous anodic $\mathrm{Al}$ oxide layer.

Two fitted peaks located at $530.7 \mathrm{eV}$ and $532.1 \mathrm{eV}$ were observed in the high resolution XPS spectrum of $\mathrm{O}$ 1s shown in Figure 6(c). This certified the formation of Al-O-Si bonds [26], respectively, of the $\mathrm{Al}_{2} \mathrm{O}_{3}$ [27].

The XPS and EDS measurements presented above are in good agreement with one another showing that $\mathrm{Si}$ atoms (coming from PDMS $/ \mathrm{H}_{2} \mathrm{O}_{2}$ medium) can be incorporated into the porous alumina layer. This result can be understood if we consider that in a classical electrochemical anodization process there are two stages in the pores formation due to the competing oxidation and dissolution processes: (a) the growth of aluminum oxide due to the counter migration of $\mathrm{Al}^{3+}, \mathrm{OH}^{-}$, and $\mathrm{O}^{2-}$ ions and (b) the dissolution of aluminum oxide at the interface between the alumina film and solution $[1,20]$.

\section{Conclusions}

In this paper, we report for the first time the formation of a porous anodic $\mathrm{Al}$ oxide layer in negative corona discharge in the presence of the PDMS $/ \mathrm{H}_{2} \mathrm{O}_{2}$ lying on the surface of the $\mathrm{Al}$ substrate. This process is favored by the enhanced infusion of $\mathrm{H}_{2} \mathrm{O}$ and $\mathrm{OH}$ radicals, respectively, by the negative ions of oxygen and neutral species $\left(\mathrm{O}_{3}\right)$ produced in negative corona discharge in air at atmospheric pressure. The $\mathrm{OH}$ radicals are produced at $\mathrm{PDMS} / \mathrm{H}_{2} \mathrm{O}_{2}$ /substrate interface as a result of the $\mathrm{H}_{2} \mathrm{O}_{2}$ and $\mathrm{H}_{2} \mathrm{O}$ decomposition. 


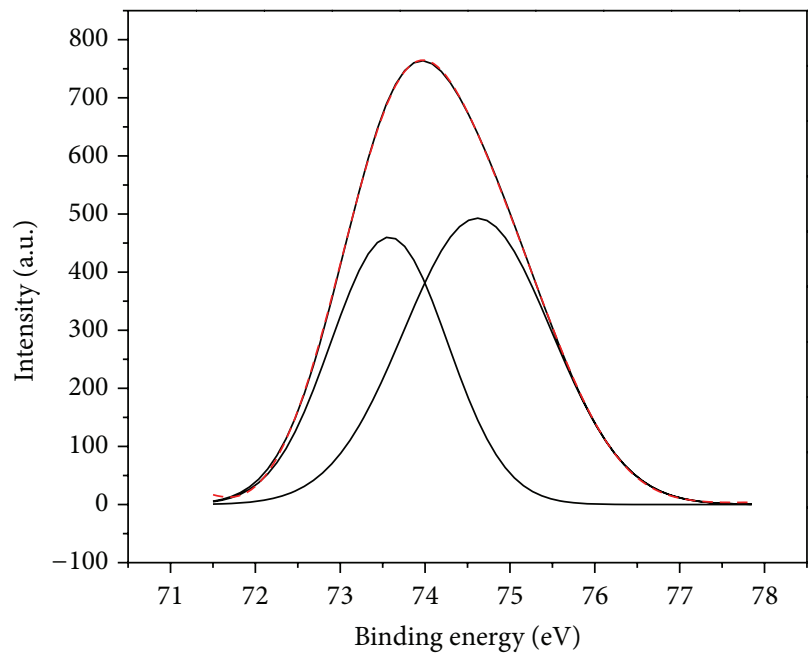

(a) $\mathrm{Al} 2 \mathrm{p}$

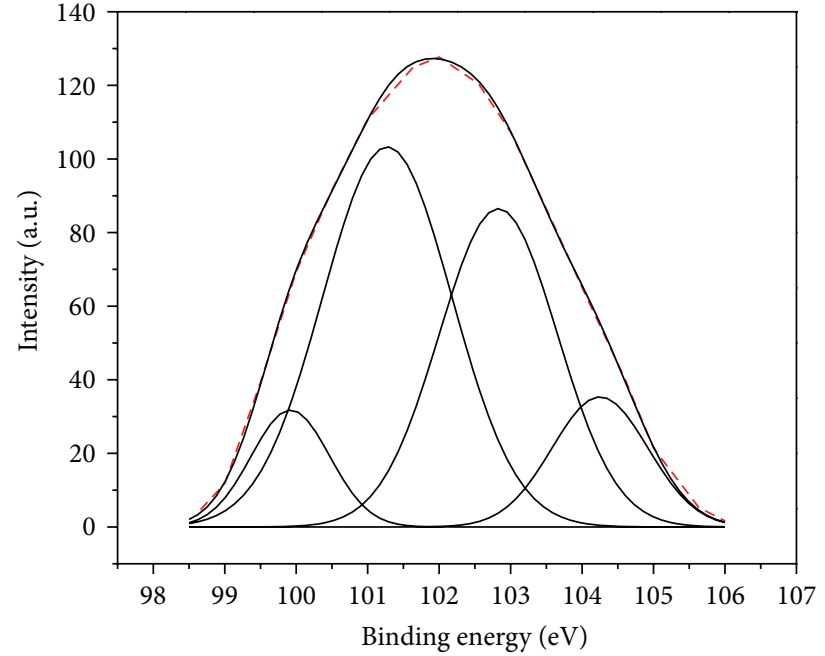

(b) Si $2 \mathrm{p}$

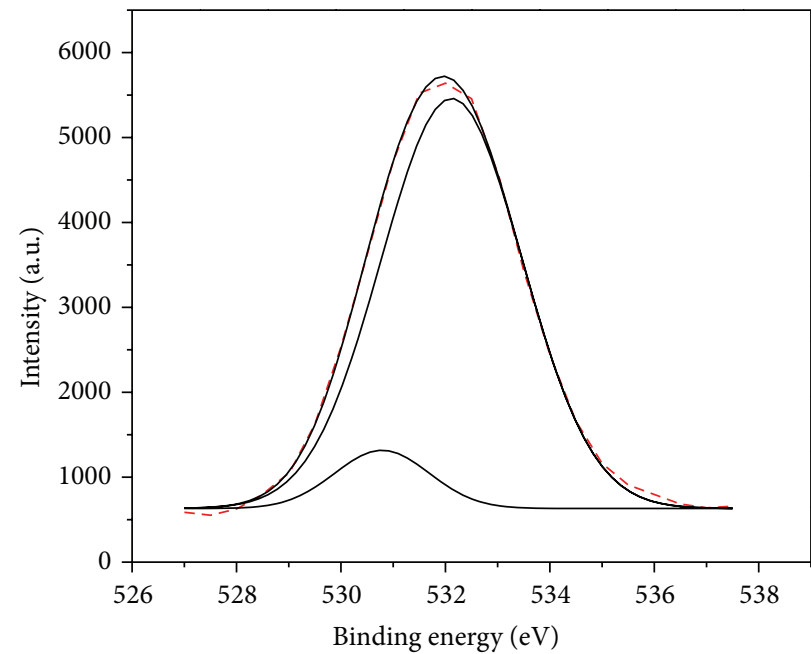

(c) $\mathrm{O} 1 \mathrm{~s}$

Figure 6: High resolution XPS spectra for (a) Al 2p, (b) Si 2p, and (c) O 1s peaks. The experimental curve is plotted in black and the theoretical fitted curve is in red dot line.

The pores present a uniform distributed structure on the surface and in the bulk of the alumina layer as the SEM analysis shows.

The XPS and EDS measurements indicate that during the pores formation mechanism the Si atoms coming from the $\mathrm{PDMS}$ are incorporated into the porous anodic $\mathrm{Al}$ oxide layer in an $\mathrm{Al}_{2} \mathrm{SiO}_{5}$ structure.

\section{Conflict of Interests}

The authors declare that there is no conflict of interests regarding the publication of this paper.

\section{Acknowledgment}

This work was supported by the PN-II-ID-PCE-2011-3-0958 and PT-PCCA-2011-3.1-1136 UEFISCDI projects.

\section{References}

[1] Z. Wu, C. Richter, and L. Menon, "A study of anodization process during pore formation in nanoporous alumina templates," Journal of the Electrochemical Society, vol. 154, no. 1, pp. E8-E12, 2007.

[2] D. Minzari, P. Møller, P. Kingshott, L. H. Christensen, and R. Ambat, "Surface oxide formation during corona discharge treatment of AA 1050 aluminium surfaces," Corrosion Science, vol. 50, no. 5, pp. 1321-1330, 2008.

[3] C. J. Ingham, J. ter Maat, and W. M. de Vos, "Where bio meets nano: the many uses for nanoporous aluminum oxide in biotechnology," Biotechnology Advances, vol. 30, no. 5, pp. 10891099, 2012.

[4] B. M. Mihalcea, "Nonlinear harmonic boson oscillator," Physica Scripta, vol. 140, Article ID 014056, 2010.

[5] B. M. Mihalcea, "Quantum parametric oscillator in a radiofrequency trap," Physica Scripta, vol. 135, Article ID 014006, 2009. 
[6] I. M. Sadiq, B. Chowdhury, N. Chandrasekaran, and A. Mukherjee, "Antimicrobial sensitivity of Escherichia coli to alumina nanoparticles," Nanomedicine: Nanotechnology, Biology, and Medicine, vol. 5, no. 3, pp. 282-286, 2009.

[7] S. L. Iconaru, P. Chapon, P. Le Coustumer, and D. Predoi, "Antimicrobial activity of thin solid films of silver doped hydroxyapatite prepared by sol-gel method," The Scientific World Journal, vol. 2014, Article ID 165351, 8 pages, 2014.

[8] C. S. Ciobanu, C. L. Popa, and D. Predoi, "Sm:HAp nanopowders present antibacterial activity against Enterococcus faecalis," Journal of Nanomaterials, vol. 2014, Article ID 780686, 9 pages, 2014.

[9] C. S. Ciobanu, S. L. Iconaru, P. Chapon, and D. Predoi, "Antimicrobial activity of silver doped hydroxyapaptite thin films," FEBS Journal, vol. 280, supplement 1, pp. 358-360, 2013.

[10] A. Groza, A. Surmeian, C. Diplasu et al., "Physico-chemical processes occurring during polymerization of liquid polydimethylsiloxane films on metal substrates under atmospheric pressure air corona discharges," Surface and Coatings Technology, vol. 212, pp. 145-151, 2012.

[11] W. E. G. Hansal, T. S. Hansal, M. Pölzler, A. Kornherr, G. Zifferer, and G. E. Nauer, "Investigation of polysiloxane coatings as corrosion inhibitors of zinc surfaces," Surface \& Coatings Technology, vol. 200, no. 9, pp. 3056-3060, 2006.

[12] K. H. Wu, C. M. Chao, T. F. Yeh, and T. C. Chang, "Thermal stability and corrosion resistance of polysiloxane coatings on 2024-T3 and 6061-T6 aluminum alloy,' Surface and Coatings Technology, vol. 201, no. 12, pp. 5782-5788, 2007.

[13] A. Groza, "Review of the processes identified during the polymerization of organic and organosilicon liquid films in atmospheric pressure air corona discharges," Romanian Reports in Physics, vol. 64, no. 4, pp. 1227-1242, 2012.

[14] A. Groza, A. Surmeian, C. Diplasu, C. Luculescu, A. Tempez, and M. Ganciu, "Evidence of aluminum oxides formation at polymer/Al substrate interface in atmospheric pressure discharges," in Proceeding of the Europhysics Conference on Atomic and Molecular Physics of Ionized Gases, 2012.

[15] A. Groza, A. Surmeian, C. Diplasu, C. Luculescu, and M. Ganciu, "Electrochemical anodization of aluminium surfaces in atmospheric pressure air corona discharge," in Proceeding of the International Conference of Plasma and Ionized Gases, 2013.

[16] Ø. Hasvold and K. H. Johansen, "The alkaline aluminium hydrogen peroxide semi-fuel cell for the hugin 3000 autonomous underwater vehicle," in Proceedings of the Workshop on Autonomous Underwater Vehicles (AUV '02), pp. 89-94, IEEE, June 2002.

[17] Z. Kozáková, Electric discharges in water solutions habilitation [Ph.D. thesis], Brno University of Technology, Faculty of Chemistry, 2011.

[18] M. Goldman and A. Goldman, Gaseous Electronics, vol. 1, Academic Press, 1978.

[19] R. S. Sigmond, "Simple approximate treatment of unipolar space-charge-dominated coronas: the Warburg law and the saturation current," Journal of Applied Physics, vol. 53, no. 2, pp. 891-898, 1982.

[20] R. Ghita, C. Logofatu, C. C. Negrila et al., Study of $\mathrm{SiO}_{2} / \mathrm{Si} \mathrm{In}-$ terface by Surface Techniques, Crystalline Silicon Properties and Uses, InTech, 2011, edited by S. Basu.

[21] G. Gusmano, G. Montesperelli, E. Traversa et al., "Magnesium aluminium spinel thin film as a humidity sensor," Sensors and Actuators B, vol. 7, no. 1-3, pp. 460-463, 1992.
[22] A. E. Hughes, M. M. Hedges, and B. A. Sexton, "Reactions at the $\mathrm{Al} / \mathrm{SiO}_{2} / \mathrm{SiC}$ layered interface," Journal of Materials Science, vol. 25, no. 11, pp. 4856-4865, 1990.

[23] X. Zhao, S. Seo, U. Lee, and K. Lee, "Controlled electrochemical dissolution of anodic aluminum oxide for preparation of openthrough pore structures," Journal of the Electrochemical Society, vol. 154, no. 10, pp. C553-C557, 2007.

[24] P. R. Anderson and W. E. Swartz Jr., "X-ray photoelectron spectroscopy of some aluminosilicates," Inorganic Chemistry, vol. 13, no. 9, pp. 2293-2294, 1974.

[25] I. F. Husein, C. Chan, S. Qin, and P. K. Chu, "The effect of highdose nitrogen plasma immersion ion implantation on silicone surfaces," Journal of Physics D: Applied Physics, vol. 33, no. 22, pp. 2869-2874, 2000.

[26] T. L. Barr, "The nature of the relative bonding chemistry in zeolites: an XPS study," Zeolites, vol. 10, no. 8, pp. 760-765, 1990.

[27] C. Hinnen, D. Imbert, J. M. Siffre, and P. Marcus, "An in situ XPS study of sputter-deposited aluminium thin films on graphite," Applied Surface Science, vol. 78, no. 3, pp. 219-231, 1994. 

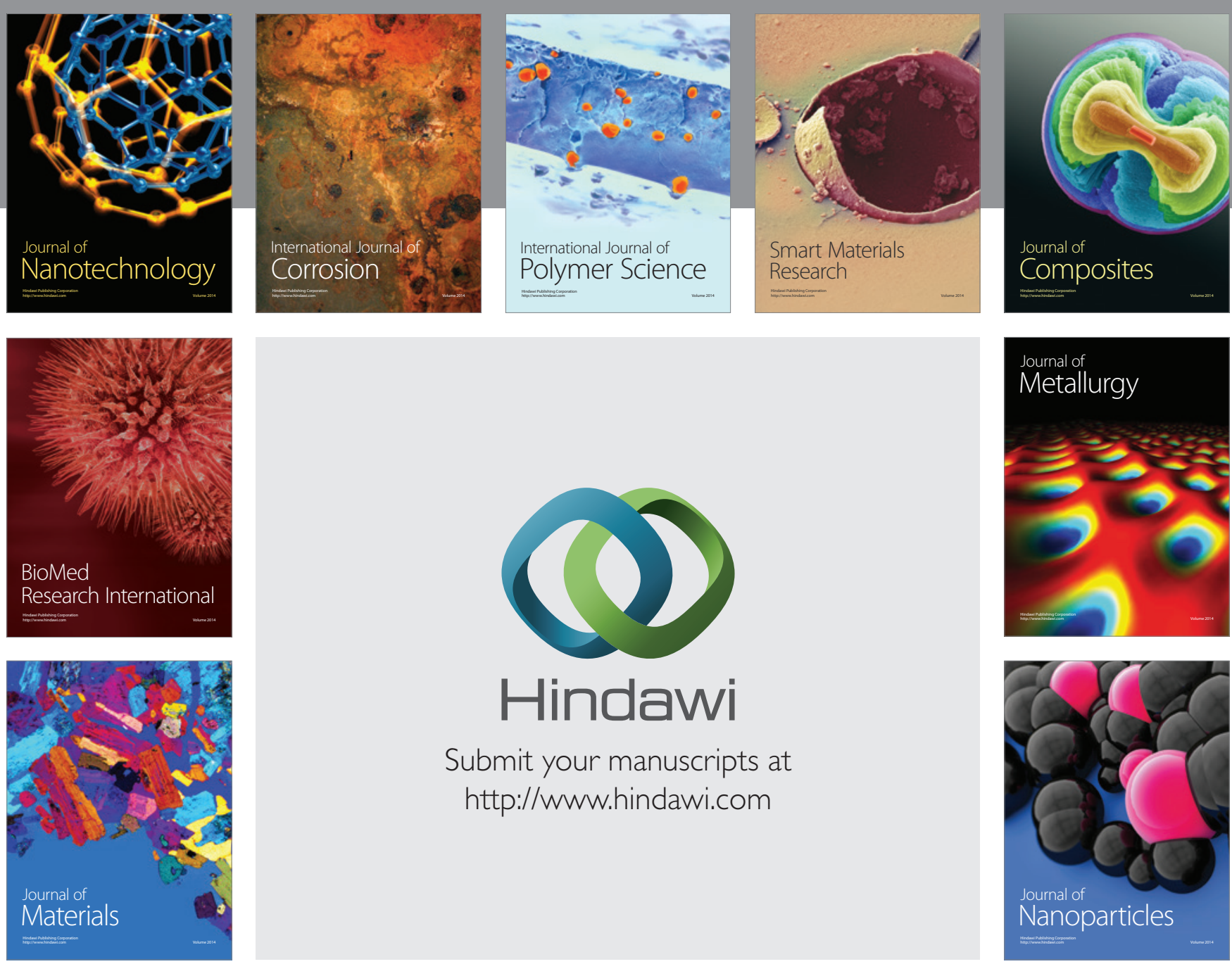

Submit your manuscripts at http://www.hindawi.com
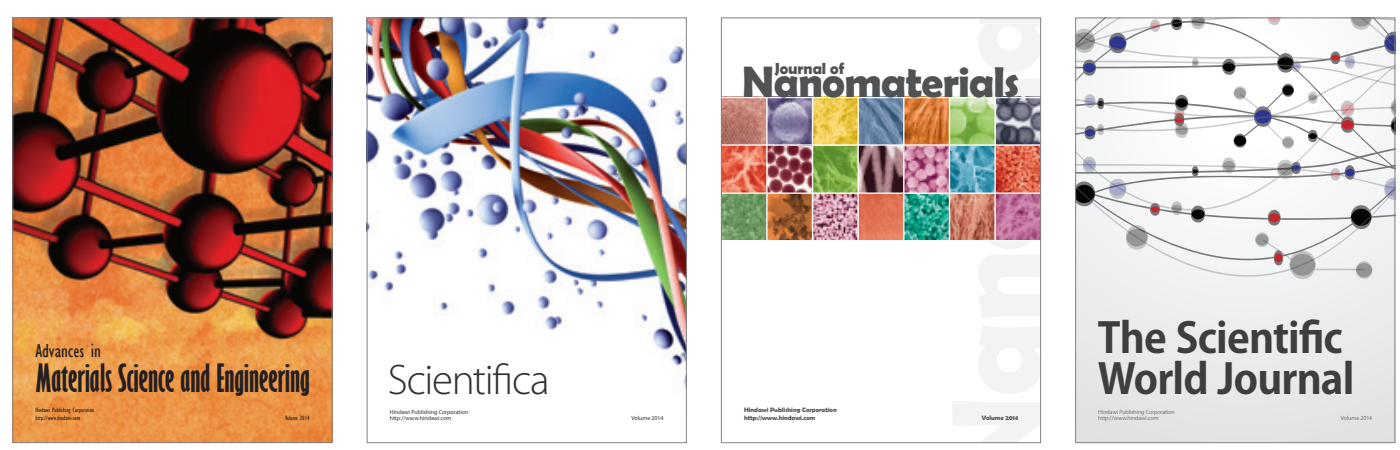

\section{The Scientific World Journal}
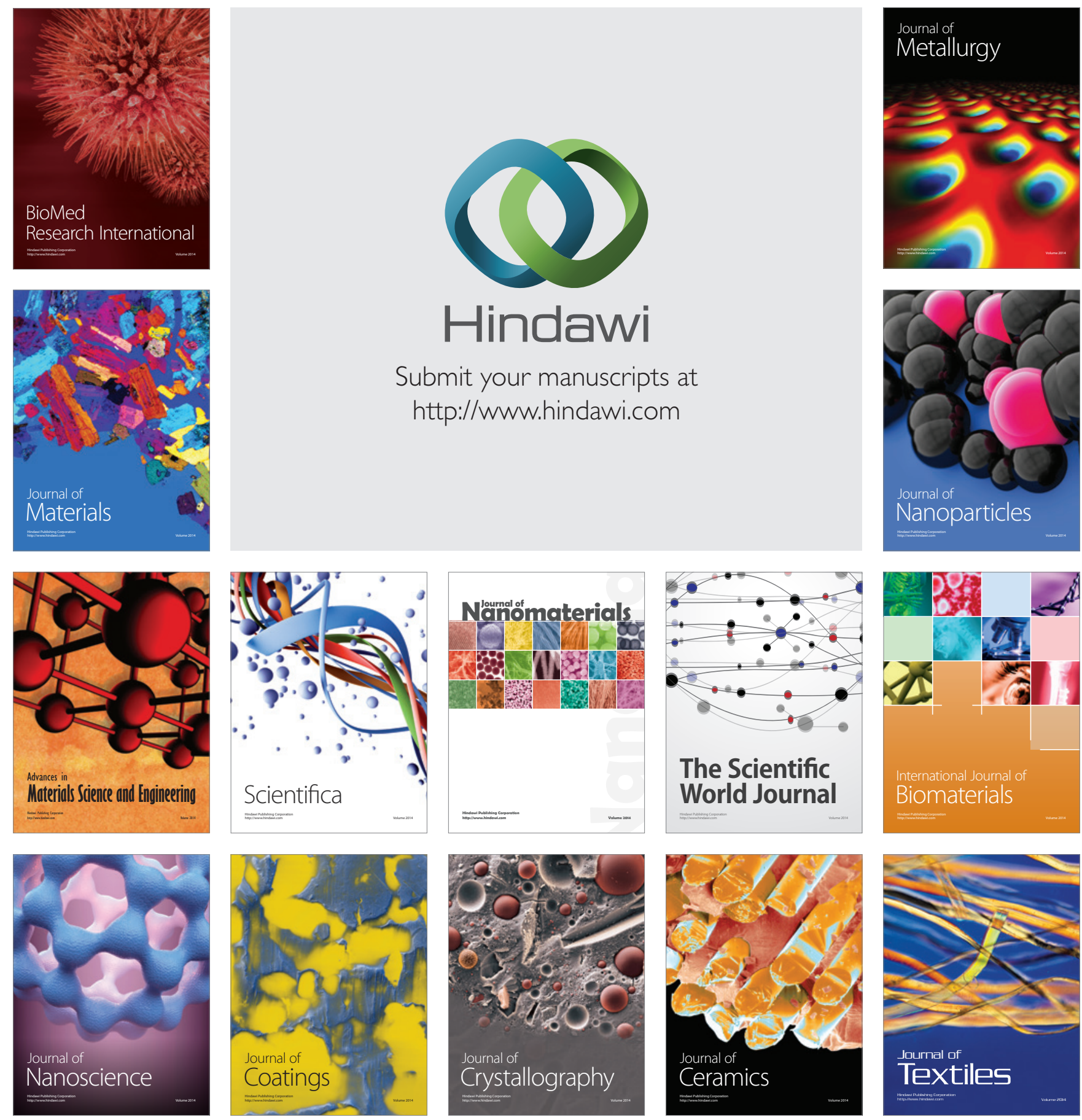